\title{
Comparison of Feeding Efficiency and Hospital Mortality between Small Bowel and Nasogastric Tube Feeding in Critically Ill Patients at High Nutritional Risk
}

\author{
Wei-Ning Wang ${ }^{1,+}+\mathbb{C}$, Chen-Yu Wang $2,3\left(\mathbb{D}\right.$, Chiann-Yi Hsu ${ }^{4}$ and Pin-Kuei Fu ${ }^{2,5,6, *,+(\mathbb{C}}$ \\ 1 Department of Food and Nutrition, Taichung Veterans General Hospital, Taichung 40705, Taiwan; \\ sherry@vghtc.gov.tw \\ 2 Department of Critical Care Medicine, Taichung Veterans General Hospital, Taichung 40705, Taiwan; \\ chestmen@gmail.com \\ 3 Department of Nursing, Hungkuang University, Taichung 43302, Taiwan \\ 4 Biostatistics Task Force of Taichung Veterans General Hospital, Taichung 40705, Taiwan; \\ chiann@vghtc.gov.tw \\ 5 College of Human Science and Social Innovation, Hungkuang University, Taichung 43302, Taiwan \\ 6 Department of Computer Science, Tunghai University, Taichung 40705, Taiwan \\ * Correspondence: yetquen@gmail.com; Tel.: +886-937-701-592 \\ + These authors contributed equally to this work.
}

Received: 3 June 2020; Accepted: 4 July 2020; Published: 6 July 2020

\begin{abstract}
Nasogastric tube enteral nutrition (NGEN) should be initiated within $48 \mathrm{~h}$ for patients at high nutritional risk. However, whether small bowel enteral nutrition (SBEN) should be routinely used instead of NGEN to improve hospital mortality remains unclear. We retrospectively analyzed 113 critically ill patients with modified Nutrition Risk in Critically Ill (mNUTRIC) score $\geq 5$ and feeding volume $<750 \mathrm{~mL} /$ day in the first week of their stay in the intensive care unit (ICU). Age, sex, mNUTRIC score, and Acute Physiology and Chronic Health Evaluation II (APACHE II) score were matched in the SBEN $(n=48)$ and NGEN $(n=65)$ groups. Through a univariate analysis, factors associated with hospital mortality were SBEN group (hazard ratio (HR), $0.56 ; 95 \%$ confidence interval (CI), 0.31-1.00), Simplified Organ Failure Assessment (SOFA) score on day 7 (HR, 1.12; 95\% CI, 1.03-1.22), and energy intake achievement rate $<65 \%$ (HR, 2.53; 95\% CI, 1.25-5.11). A multivariate analysis indicated that energy intake achievement rate $<65 \%$ on the third follow-up day (HR, 2.29; $95 \%$ CI $1.12-4.69$ ) was the only factor independently associated with mortality. We suggest initiation of SBEN on the seventh ICU day before parenteral nutrition initiation for critically ill patients at high nutrition risk.
\end{abstract}

Keywords: critically ill patients; feeding efficiency; high nutritional risk; hospital mortality; small bowel enteral nutrition

\section{Introduction}

Malnutrition and undernutrition have been recognized as a highly prevalent problem during intensive care unit (ICU) stays [1,2]. Up to 50-60\% of critically ill patients are reported to experience energy and protein deficits during their ICU stay, which are correlated with morbidity and mortality $[3,4]$. No consensus exists regarding a gold standard tool for identifying ICU patients who are at high risk and are malnourished [5]. However, screening tools such as the Nutritional Risk Score, Nutrition Risk in Critically Ill (NUTRIC) assessment score, and modified NUTRIC (mNUTRIC) score have been widely applied to identify high-risk patients and enable initiation of early enteral nutrition (EN) 
therapy in the ICU [6-12]. Patients with mNUTRIC scores of more than 5 points are identified as being at high nutritional risk and urgently requiring additional energy support to reduce the likelihood of mortality $[8,13,14]$. In our previous study, an energy achievement rate of lower than $65 \%$ in patients admitted to ICU was associated with a higher risk of mortality [15], and targeted energy intake was also a mortality predictor in this population [13]. Therefore, a systemic approach to recognizing ICU patients at high nutritional risk and initiating early EN in these patients has become the standard of care for decreasing morbidity, pneumonia incidence, and even hospital mortality in critically ill patients $[5-7,16-18]$.

The current guidelines recommend that early nasogastric tube enteral nutrition (NGEN) should be initiated within $48 \mathrm{~h}$ of ICU admission because this route is easier to facilitate initiation of EN as soon as possible [5-7,11]. However, small bowel EN (SBEN) has theoretical advantages over stomach EN because it not only decreases the risks of gastroesophageal reflux and aspiration pneumonia, but also delivers more nutrients than does NGEN [19-23]. The current guidelines including the European Society for Clinical Nutrition and Metabolism (ESPEN), the American Society for Parenteral and Enteral Nutrition (ASPEN), and the Society of Critical Care Medicine (SCCM) guidelines strongly recommend NGEN for EN initiation in critically ill patients at high risk and a shift to SBEN when the patient has developed intolerance of NGEN despite the administration of prokinetic agents [5-7]. For patients unable to meet the $>60 \%$ achievement rate for protein and energy intake through the EN alone, supplemental parenteral nutrition (PN) can be considered after 7-10 days of EN [6,7].

Our previous study suggested the evaluation of the role of SBEN on the seventh day of the ICU stay for those with energy achievement rates of less than $60 \%$ [9]. We demonstrated that the feeding volume and achievement rates (\%) of protein and energy intake were significantly higher after SBEN on the 10th day of the ICU stay [8]. We also found that an energy achievement rate lower than $65 \%$ on the third day after SBEN (the 10th day of the ICU stay) increased the mortality risk by a factor of 4.97 [8]. However, whether SBEN should be routinely used instead of NGEN for undernourished critically ill patients and to improve the hospital mortality remains unclear. The current retrospective study compared the feeding efficiency and hospital mortality of two feeding routes (maintaining NGEN or shifting to SBEN) on the seventh ICU day in ICU patients who were undernourished and at high nutritional risk.

\section{Materials and Methods}

\subsection{Study Design and Ethic Approval}

This retrospective, case-control study was conducted in the respiratory intensive care unit (RICU) of Taichung Veterans General Hospital from January 2014 to December 2015 in Central Taiwan. The Institutional Review Board of Taichung Veterans General Hospital reviewed and approved the study protocol (IRB number, CE16028A; date of approval, 29 January 2016). The current study waived the requirement for informed patient consent due to the availability of all delinked data from an electronic medical record system and the study design was a retrospective analysis.

\subsection{Patient, Clinical Setting, Nutrition Evaluation, and Routine}

The RICU is an adult medical ICU with 24 beds servicing patients with pneumonia accompanied by various conditions—such as septic shock and acute respiratory distress syndrome-of various severities. It has a full-time registered dietitian to conduct nutritional risk and target evaluation and provide suggestions for routine application. Serial information including mNUTRIC score, nutritional goals, and the achievement rate of energy target are routinely determined for each critically ill patient by the full-time dietitian. The mNUTRIC score has five components: age, number of comorbidities, Simplified Organ Failure Assessment (SOFA) score, Acute Physiology and Chronic Health Evaluation II (APACHE II) score, and days in hospital before ICU admission [24]. For every patient admitted to the RICU, the dietitian determines their mNUTRIC score (0-9 points) within $48 \mathrm{~h}$ of ICU admission 
and records it in the electronic medical record, as described in our previous study $[8,13,15]$. The target energy requirement was $25-30 \mathrm{kcal} / \mathrm{kg} /$ day and the protein intake target was $1.2 \mathrm{~g} / \mathrm{kg} /$ day in accordance with the 2016 ASPEN/SCCM guidelines [6,7].The achievement rate (\%) of energy was defined as follows: (actual energy intake/estimated energy requirement) $\times 100$; the achievement rate $(\%)$ of protein was adjusted as follows: (actual protein intake/estimated protein requirement) $\times 100[8,13,15]$.

Early EN was initiated on the first day for all patients admitted to the RICU except in some clinical contraindications. On the seventh ICU day, a transpyloric tube for SBEN was an option in patients with high nutritional risk (mNUTRIC $\geq 5$ ) and severe malnutrition (energy target achievement rate $<30 \%$ or feeding volume $<750 \mathrm{~mL} /$ day) after trying prokinetic agents. Some of these patients were shifted to SBEN, but NGEN feeding was retained for others, because the use of SBEN for undernourished patients on the seventh ICU day is not mandatory according to the current guidelines. These clinical situations thus enabled us to analyze the two feeding routes on the seventh ICU day and their effects on feeding efficiency and mortality. From January 2014 to December 2015, a total of 113 patients with malnutrition and at high nutritional risk were retrospectively enrolled in the analysis and were classified into SBEN $(n=48)$ and NGEN $(n=65)$ groups through matching according to age, sex, mNUTRIC score, and APACHE II score (Supplementary Figure S1 revealed the study flow.).

\subsection{Data Collection, Adjustment, and Outcome Measures}

Data were collected on age, sex, body mass index (BMI), severity of illness (SOFA and APACHE II scores), mNUTRIC score, major comorbidities, and Charlson Comorbidity Index (CCI). The primary outcome was feeding efficiency, including average energy intake achievement rate (\%); hospital mortality was the secondary outcome. The index date was the seventh day of the ICU stay, which was the day defining whether a patient with critical illness and malnutrition was placed in the SBEN or NGEN group. Those who had received transpyloric tube insertion were enrolled into the SBEN group. Daily energy intake was recorded from the index day (the seventh ICU day) until 7 days later (the 14th ICU day). As in our previous report [8], the serial nutrition parameters 3 days after the index date were employed to compare the feeding efficiency of the SBEN and NGEN groups. Feeding efficiency was evaluated by the following six parameters: (1) actual feeding volume (mL/day), (2) actual energy intake (kcal/day), (3) actual protein intake (g/day), (4) actual protein intake (g/kg/body weight (BW)), (5) energy intake achievement rate (\%), and (6) protein intake achievement rate (\%). The primary outcome was the comparison of feeding efficiency between the SBEN and NGEN groups. The secondary outcome was factors associated with hospital mortality in ICU patients with mNUTRIC score $\geq 5$ and feeding volume $<750 \mathrm{~mL} /$ day. We also validated the power of hospital mortality prediction in this setting because an energy achievement rate of $<65 \%$ on the third day after the index date (the 10th ICU day) was demonstrated to be an outcome predictor in our other study [8].

\subsection{Statistical Analysis}

Categorical variables are presented as frequencies and percentages. The chi-squared test was used to determine significance. The Mann-Whitney $U$ test was applied to determine differences between groups for data with nonparametric distribution, and the results are presented as the median and interquartile range (IQR). Factors associated with hospital mortality were assessed through Cox regression analysis. The strength of an association is presented as the hazard ratio (HR) and $95 \%$ confidence interval (CI). All tests were two sided, with $p<0.05$ considered significant. The SPSS statistical software package (version 24.0; International Business Machines Corp, Armonk, NY, USA) was used for all statistical analyses.

\section{Results}

Table 1 reveals a comparison of demographic characteristics, severity scores, comorbidities, energy intake, and hospital mortality between the SBEN and NGEN groups. The median mNUTRIC score of the cohort was 7 (IQR, 5.25-8 in the SBEN group and 5.5-8 in the NGEN group), indicating that these 
patients were at high nutritional risk. The APACHE II (27.0 and 30.0 for the SBEN and NGEN groups, respectively) and SOFA (10 and 10 for the SBEN and NGEN groups, respectively) scores also indicated the high clinical severity of disease in this cohort. However, cardiovascular disease $(64.58 \%$ and $26.15 \%$ in the SBEN and NGEN groups, respectively, $p<0.001)$ and cancer $(45.83 \%$ and $12.31 \%$ in the SBEN and NGEN groups, respectively, $p<0.001$ ) were more common in the SBEN group than the NGEN group; liver cirrhosis (22.92\% and $55.38 \%$ in the SBEN and NGEN groups, respectively, $p=0.001$ ) was less common in the SBEN group. The overall hospital mortality rate exhibited no significant difference between these two groups (43.75\% and $43.08 \%$ in the SBEN and NGEN groups, respectively, $p>0.05)$. The achievement rate (\%) of daily average energy intake on days 2-7 was significantly higher in the SBEN group than the NGEN group on each observation day. As shown in Table 1, the average energy achievement rate was higher than $60 \%$ in the SBEN group on the fourth day, but remained lower than $60 \%$ until the seventh day in the NGEN group. Using the energy achievement index parameter of more than $65 \%$ on the third day (the 10th ICU day) as the objective goal, $45.83 \%$ of patients achieved the goal in the SBEN group, but only $26.15 \%$ reached the goal in the NGEN group, a significant difference $(p=0.048)$.

Table 1. Demographic characteristics, severity scores, comorbidities, and clinical outcomes for all malnourished patients in the intensive care unit (ICU).

\begin{tabular}{|c|c|c|c|}
\hline Variables & SBEN Group $(n=48)$ & NGEN Group $(n=65)$ & $p$-Value \\
\hline Age (year) & $70.45(59.75-79.94)$ & 74.17 (54.63-85.12) & 0.423 \\
\hline Gender-Male $(n, \%)^{\text {a }}$ & $31(64.58 \%)$ & $48(73.85 \%)$ & 0.393 \\
\hline Body mass index $\left(\mathrm{kg} / \mathrm{m}^{2}\right)$ & $23.62(21.29-27.32)$ & $22.77(21.1-25.05)$ & 0.238 \\
\hline mNUTRIC score & $7.00(5.25-8)$ & $7.0(5.5-8)$ & 0.491 \\
\hline APACHE II score & $27.00(24-32.75)$ & $30.00(27-33)$ & 0.156 \\
\hline SOFA-day 1 & $10.00(8-12.75)$ & $10.00(6.5-13)$ & 0.875 \\
\hline SOFA-day $3(n=47$ vs. 64$)$ & $9.00(6-12)$ & $10.00(8-13)$ & 0.172 \\
\hline SOFA—day 7 ( $n=46$ vs. 64$)$ & $8.5(5-11)$ & $9.0(7-11)$ & 0.490 \\
\hline CCI & $2.5(1-4)$ & $0.0(0-2)$ & $<0.001^{* *}$ \\
\hline \multicolumn{4}{|l|}{ Comorbidity $(n, \%)^{\mathrm{a}}$} \\
\hline Diabetes mellitus & $13(27.08 \%)$ & $20(30.77 \%)$ & 0.828 \\
\hline Chronic kidney disease & $9(18.75 \%)$ & $14(21.54 \%)$ & 0.898 \\
\hline Cardiovascular disease & $31(64.58 \%)$ & $17(26.15 \%)$ & $<0.001^{* *}$ \\
\hline Cancer & $22(45.83 \%)$ & $8(12.31 \%)$ & $<0.001 * *$ \\
\hline Liver cirrhosis & $11(22.92 \%)$ & $36(55.38 \%)$ & $0.001 * *$ \\
\hline $\begin{array}{l}\text { Average energy intake } \\
\text { achievement rate (\%) after } \\
\text { enrollment }\end{array}$ & & & 1.000 \\
\hline 2nd day & $57.16(36.29-70.69)$ & $41.35(30.16-65.12)$ & \\
\hline 3rd day & $55.91(41.5-75.49)$ & $44.16(30.85-64.41)$ & $0.039 *$ \\
\hline 4th day & $60.29(41.29-75.11)$ & $49.02(32.36-66.74)$ & $0.015 *$ \\
\hline 5 th day & $63.36(43.2-78.62)$ & $49.45(32.05-69.46)$ & $0.026 *$ \\
\hline 6th day & $63.63(45.5-81.01)$ & $51.12(32.24-71.99)$ & 0.015 * \\
\hline 7th day & $65.20(48.91-84.47)$ & $55.12(32.57-75.35)$ & $0.022 *$ \\
\hline $\begin{array}{c}\text { Average energy intake } \\
\text { achievement rate }(\%) \geq 65 \%(3 \\
\text { days after the index day) }(n, \%)^{\text {a }}\end{array}$ & $22(45.83 \%)$ & $17(26.15 \%)$ & $0.031 *$ \\
\hline Hospital mortality $(n, \%)^{\mathrm{a}}$ & $21(43.75 \%)$ & $28(43.08 \%)$ & $0.048 *$ \\
\hline
\end{tabular}

Table 2 presents a comparison of the feeding efficiency of the SBEN and NGEN groups. Actual daily energy parameters represent the feeding efficiency on the third observation day, including actual feeding volume $(\mathrm{mL} /$ day), actual energy intake ( $\mathrm{kcal} /$ day), actual protein intake $(\mathrm{g} /$ day), actual protein intake $(\mathrm{g} / \mathrm{kg} / \mathrm{BW})$, energy intake achievement rate $(\%)$, and protein achievement rate $(\%)$. All feeding 
parameters were significantly higher in the SBEN group than the NGEN group (Table 2). The energy intake achievement rate (\%) in the SBEN group significantly increased day by day compared with that in the NGEN group ( $p=0.021$; Figure 1$)$.

Table 2. Comparison of feeding efficiency between SBEN and NGEN groups on the third day after enrollment in malnourished, critically ill, ICU patients.

\begin{tabular}{|c|c|c|c|}
\hline Variables & SBEN Group $(n=48)$ & NGEN Group $(n=65)$ & $p$-Value \\
\hline $\begin{array}{l}\text { Actual feeding volume } \\
\text { (mL/day) }\end{array}$ & 992.88 (706.44-1191.38) & $824.50(541.38-1054.88)$ * & 0.025 * \\
\hline $\begin{array}{c}\text { Actual energy intake } \\
\text { (kcal/day) }\end{array}$ & 921.15 (635.79-1172.81) & $707.40(487.24-949.39) * *$ & $0.004^{* *}$ \\
\hline $\begin{array}{l}\text { Actual protein intake } \\
\text { (g/day) }\end{array}$ & $36.37(25.43-46.91)$ & $28.30(19.49-37.98) * *$ & $0.005^{* *}$ \\
\hline $\begin{array}{c}\text { Actual protein intake } \\
(\mathrm{g} / \mathrm{kg} / \mathrm{BW})\end{array}$ & $0.60(0.41-0.74)$ & $0.49(0.31-0.69)$ * & 0.029 * \\
\hline $\begin{array}{c}\text { Energy intake } \\
\text { achievement rate }(\%)\end{array}$ & $60.29(41.29-75.11)$ & $49.02(32.36-66.74) *$ & 0.026 * \\
\hline $\begin{array}{c}\text { Protein intake } \\
\text { achievement rate }(\%)\end{array}$ & $49.63(34.16-62.01)$ & $40.85(25.78-57.18)$ * & 0.029 * \\
\hline
\end{tabular}

Values are median (interquartile range (IQR)). Mann-Whitney $\mathrm{U}$ test. ${ }^{*} p<0.05,{ }^{* *} p<0.01$.

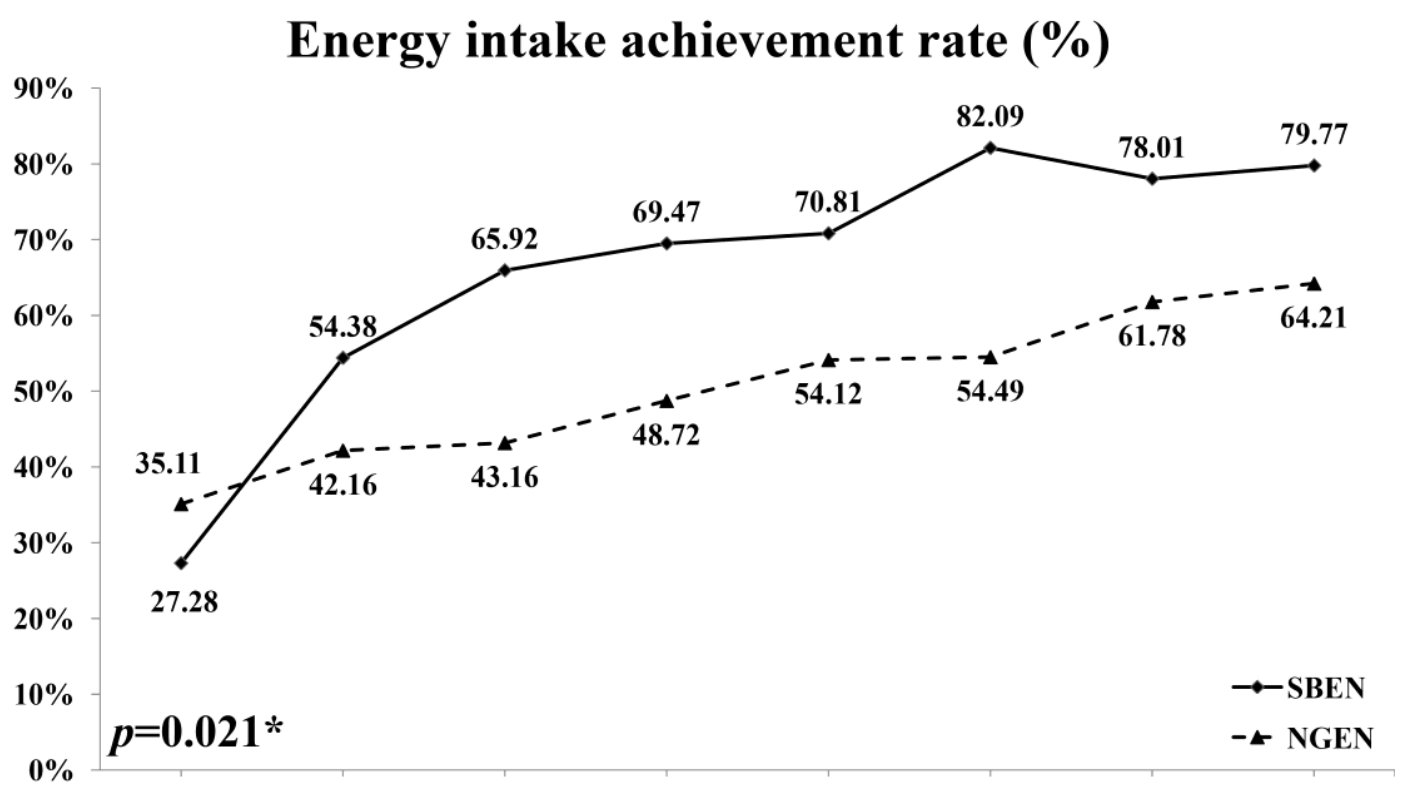

Day 0 Day 1 post Day 2 post Day 3 post Day 4 post Day 5 post Day 6 post Day 7 post

Figure 1. Achievement rate of energy intake for SBEN and NGEN groups. $p=0.021$

The parameters of surviving and nonsurviving patients were compared (Table 3). The nonsurviving patients had higher SOFA scores on the seventh ICU day and lower energy intake achievement rates (\%) on each day subsequent to the enrollment day. Age, sex, BMI, mNUTRIC score, APACHEII score, and comorbidities were not significantly different between the survival and nonsurvival groups. In the survival group, the median energy intake was $60 \%$ on the fourth day (the 11th ICU day). By contrast, the median energy intake achievement in the nonsurvival group remained at lower than $50 \%$, even on the seventh day after enrollment (the 14th ICU day; Table 3).

Factors associated with mortality by Cox regression analysis are shown in Table 4. A univariate analysis identified only three factors associated with mortality: SBNE group (HR, 0.56; 95\% CI, 0.31-0.997; $p=0.049)$, SOFA score on the seventh ICU day (HR, 1.12; 95\% CI, 1.03-1.22; $p=0.009)$, 
and energy achievement rate $<65 \%$ on the third day after enrollment (the 10th ICU day; HR, 2.53; $95 \% \mathrm{CI}, 1.25-5.11 ; p=0.01$ ). A multivariate analysis indicated that energy intake achievement rate $<65 \%$ on the third day after enrollment (HR, 2.29; 95\% CI, 1.12-4.69) was the only predictive factor that differed significantly between the survival and nonsurvival groups. In this cohort, an energy achievement rate $>65 \%$ was associated with lower 60-day, 90-day, and hospital mortality after adjustment for age, sex, BMI, and SOFA and APACHE II scores in patients at high nutritional risk (mNUTRIC $\geq 5$; Figure 2).

Table 3. Comparison of survivors and nonsurvivors according to hospital mortality in malnourished, critically ill, ICU patients.

\begin{tabular}{|c|c|c|c|}
\hline Variables & Nonsurvival $(n=49)$ & Survival $(n=64)$ & $p$-Value \\
\hline Group $(n, \%)^{\mathrm{a}}$ & & & 1.000 \\
\hline SBEN group & $37(75.51 \%)$ & 27 (42.19\%) & \\
\hline NGEN group & $22.59(57.14 \%)$ & $37(57.81 \%)$ & \\
\hline Age (year) & $72.13(55.47-83.26)$ & $73.03(60.54-82.22)$ & 0.498 \\
\hline Gender-Male $(n, \%)^{a}$ & $37(75.51 \%)$ & $42(65.63 \%)$ & 0.353 \\
\hline Body mass index $\left(\mathrm{kg} / \mathrm{m}^{2}\right)$ & $22.59(20.44-26.67)$ & $23.52(21.41-26.21)$ & 0.412 \\
\hline mNUTRIC score & $7.00(6-8)$ & $7.00(5-8)$ & 0.255 \\
\hline APACHE II score & $30.00(26.5-34)$ & $28.00(24-32)$ & 0.176 \\
\hline SOFA-day 1 & $10.00(8-13.5)$ & $10.00(6-12.75)$ & 0.257 \\
\hline SOFA-day 3 & $11.00(8-13)$ & $9.00(6-12)$ & 0.082 \\
\hline SOFA-day 7 & $10.00(7-13)$ & $8.00(6-10) * *$ & $0.007^{* *}$ \\
\hline CCI & $1.00(0-3)$ & $2.00(0-3.75)$ & 0.333 \\
\hline \multicolumn{4}{|l|}{ Comorbidity $(n, \%)^{\text {a }}$} \\
\hline Diabetes mellitus & $11(22.45 \%)$ & $22(34.38 \%)$ & 0.241 \\
\hline Chronic kidney disease & $13(26.53 \%)$ & $10(15.63 \%)$ & 0.234 \\
\hline Cardiovascular disease & $20(40.82 \%)$ & $28(43.75 \%)$ & 0.904 \\
\hline Cancer & $12(24.49 \%)$ & $18(28.13 \%)$ & 0.827 \\
\hline Liver cirrhosis & $19(38.78 \%)$ & $28(43.75 \%)$ & 0.735 \\
\hline Obstructive pulmonary disease & $17(34.69 \%)$ & $20(31.25 \%)$ & 0.854 \\
\hline \multicolumn{4}{|l|}{$\begin{array}{c}\text { Average of energy intake } \\
\text { achievement rate }(\%) \\
\text { post-enrollment }\end{array}$} \\
\hline 2nd day & $43.69(24.9-58.88)$ & $49.44(35.44-70.69) *$ & $0.042 *$ \\
\hline 3rd day & $40.63(24.43-63.04)$ & $55.91(38.98-72.22) * *$ & $0.009 * *$ \\
\hline 4th day & $41.45(27.78-66.7)$ & $59.76(40.3-76.73) * *$ & $0.005^{* *}$ \\
\hline 5 th day & $44.55(26.86-68.16)$ & $60.80(44.13-84.31) * *$ & $0.002 * *$ \\
\hline 6th day & $45.97(24.78-66.57)$ & $63.45(48.93-83.84)^{* *}$ & $0.001 * *$ \\
\hline 7th day & $48.99(25.01-67.34)$ & $66.07(50.68-84.47) * *$ & $<0.001 * *$ \\
\hline
\end{tabular}

Values are median (IQR). Mann-Whitney U test. ${ }^{a}$ Chi-squared test. ${ }^{*} p<0.05,{ }^{* *} p<0.01$.

Table 4. Cox regression analysis for factors associated with hospital mortality.

\begin{tabular}{ccc}
\hline Variables & Univariate Analysis & Multivariate Analysis \\
\hline & HR $(\mathbf{9 5} \% \mathbf{C I})$ & HR (95\% CI) \\
\hline Age (year) & $0.99(0.98-1.01)$ & \\
Group (SBEN vs. NGEN) & $0.56(0.31-0.997) *$ & $0.65(0.36-1.18)$ \\
Gender (Female vs. Male) & $0.62(0.32-1.20)$ & \\
Body mass index (kg/m2) & $0.97(0.91-1.04)$ & \\
mNUTRIC score & $0.91(0.72-1.14)$ & \\
APACHE II score & $1.01(0.96-1.06)$ & \\
SOFA—day 1 & $0.99(0.92-1.07)$ & \\
SOFA—day 3 & $1.05(0.97-1.13)$ & \\
SOFA—day 7 & $1.12(1.03-1.22) * * 29(1.12-4.69) *$ \\
Energy intake achievement rate & & \\
$(\%)(3$ days after the index day) & $2.53(1.25-5.11)^{*}$ & \\
$(<65 \%$ vs. $\geq 65 \%)$ & &
\end{tabular}




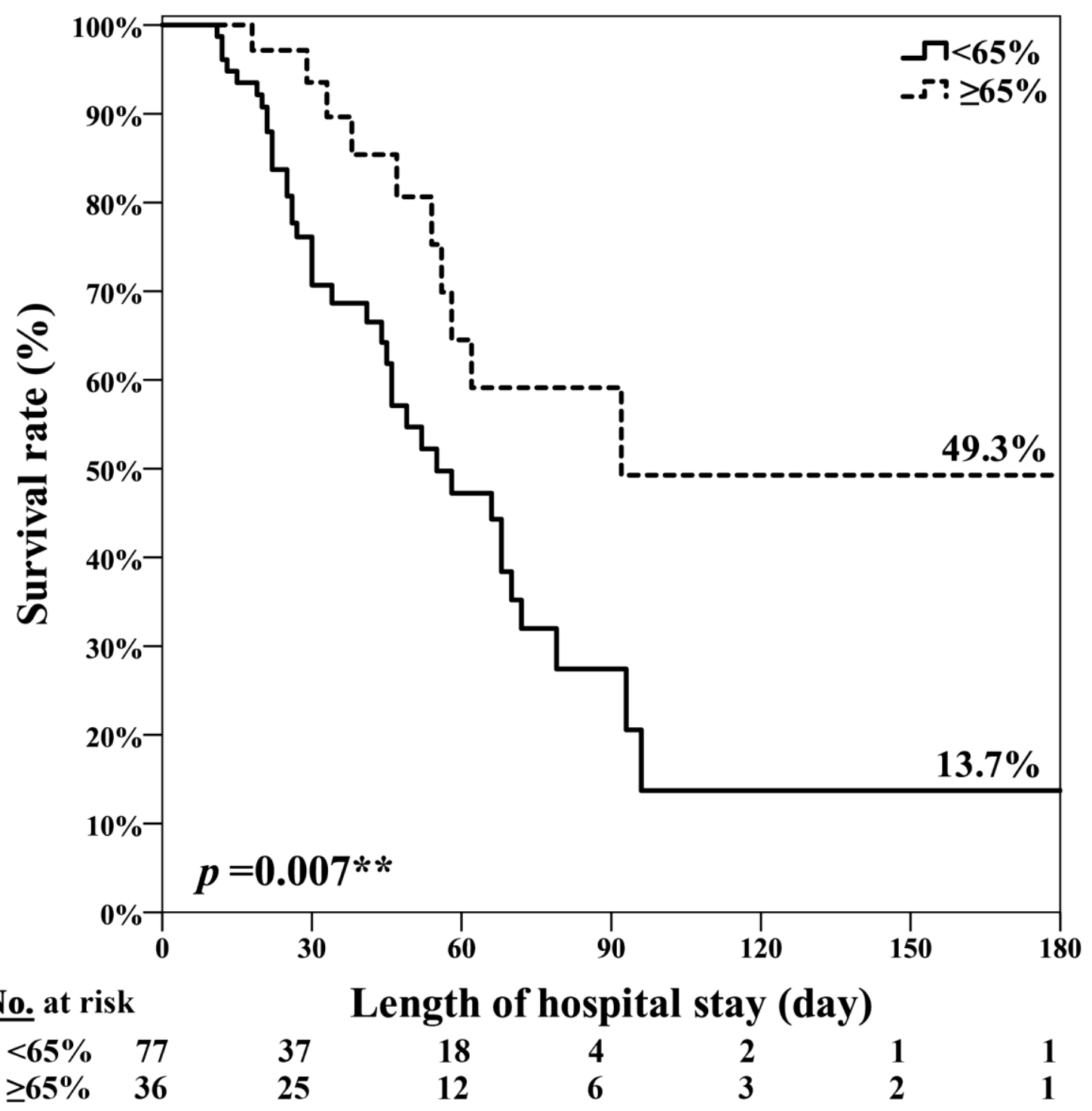

Figure 2. Energy achievement rate $\geq 65 \%$ on the 10 th ICU day was significantly associated with lower hospital mortality in patients at high nutritional risk. ${ }^{* *} p=0.007$.

\section{Discussion}

The present study reports three major findings regarding critically ill patients admitted to the ICU with malnourishment and high nutritional risk. First, after 7 days of stomach EN, the initiation of adjuvant SBEN improved energy delivery and had potential benefits in relation to hospital mortality compared with continued stomach EN. Second, the feeding efficiency increased significantly after SBEN initiation and resulted in the nutritional goal being achieved within 3 days. Third, achievement of $65 \%$ of the energy requirements by day 3 after SBEN initiation (on the 10th ICU day) was the key factor associated with survival. If a patient does not reach the goal within 3 days of SBEN initiation, we suggest that PN should be considered to improve the energy intake achievement rate.

The current guidelines-including the ASPEN/SCCM and ESPEN guidelines and the consensus statement of the Asia-Pacific and Middle East regions-recommend that every critically ill patient staying in the ICU for more than $48 \mathrm{~h}$ should be considered as being at risk of malnutrition, and a systemic approach to, as well as evaluation of, nutritional risk is suggested [5,6,11]. EN should be initiated within $48 \mathrm{~h}$ to provide nutritional support to critically ill patients who are unable to maintain 
volitional intake [5-7]. The current evidence does not suggest routine feeding through SBEN [19]. Accordingly, NGEN is recommended as the standard approach for early EN, and SBEN can be used as adjuvant therapy for those with gastric feeding intolerance that cannot be resolved with prokinetic agents [5-7]. In fact, studies have demonstrated that SBEN provides greater feeding efficiency than NGEN [19-21,23]. However, the right time to shift from NGEN to SBEN remains unclear in the current guidelines. Regarding actual clinical practice, we conduct a feeding protocol to evaluate the energy intake achievement rate at the end of the first week of an ICU stay, and this evaluation enables initiation of SBEN on the eighth ICU day as an option in ICU care [8]. Therefore, all patients enrolled in the present cohort had high mNUTRIC score (median mNUTRIC score, 7; IQR, 5.25-8) and low energy intake achievement rate $(<50 \%$ of the target goal or feeding volume $<750 \mathrm{~mL} /$ day $)$ even though NGEN was started within $48 \mathrm{~h}$ of ICU admission. To the best of our knowledge, the present study, which initiated SBEN as adjuvant therapy on the 7th ICU day to improve energy delivery compared with maintenance of NGEN, is the first data-based report to examine critically ill, ICU patients at high nutritional risk.

Another major issue overlooked in the guidelines is the optimal time at which to decide that the SBEN approach has failed and feeding route should be switched from SBEN to supplemental PN or total PN. Our previous study suggested that on the third day after SBEN initiation, the optimal energy intake achievement rate was higher than $65 \%$ [8]. For critically ill patients for whom NGEN has failed and have been shifted to SBEN on the eighth ICU day, an energy achievement rate of $<65 \% 3$ days after SBEN initiation was significantly associated with increased mortality (odds ratio, $4.97 ; 95 \%$ CI, 1.44-17.07) [8]. The 2019 ESPEN guidelines recommend that PN should not be started until all strategies to maximize EN tolerance have been attempted [5]. Heidegger et al. suggested that starting supplementary PN on the fourth day after ICU admission may reduce nosocomial infections and improve clinical outcomes in patients for whom EN is insufficient [25]. Some studies have suggested initiating EN plus PN between the fourth and seventh days in the ICU [26-28]. However, the 2016 ASPEN/SCCM guidelines recommend considering the initiation of supplemental PN only if $>60 \%$ energy and protein intake achievement are not achieved after 7-10 days of EN because initiating PN before this time has no benefits [6,7]. Braunschweig et al. published research on the timing and doses of energy received by patients with acute lung injury, inferring that higher later (days $\geq 8$ ) energy intake may reduce the mortality risk [29]. Therefore, the optimal time point for administration of supplementary PN with the aim of meeting full energy requirements and whether SBEN should be attempted before a patient is shifted to PN remain unclear. Our data suggest that for critically ill patients with mNUTRIC score $\geq 5$ and poor feeding achievement rate $(<50 \%$ of target goal or feeding volume $<750 \mathrm{~mL} /$ day) using gastric tube feeding, SBEN for 3 days is an option prior to PN initiation.

The final point that merits discussion is whether SBEN has advantages in terms of mortality. The literature shows that adequate nutritional support has a significant mortality benefit in those at high risk of malnutrition and who are critically ill [14,30]. Our study conducted in 2019 also suggested that energy requirements achieving $<65 \%$ within 3 days of SBEN initiation is the independent factor associated with mortality (OR, 4.97; 95\% CI, 1.44-17.07) in malnourished and high nutritional risk populations [8]. Our previous studies suggested that critically ill patients at high nutritional risk who receive at least $65 \%$ of their energy intake requirements and consume at least $800 \mathrm{kcal} /$ day exhibit significantly lower 14-day, 28-day, and hospital mortality rates [13,15]. However, in populations at low nutritional risk (mNUTRIC score $<5)$, copious evidence indicates no survival benefits from full nutritional support $[13,24,30-32]$. This phenomenon is due to the strong correlation of suboptimal energy delivery with increased nosocomial infection, longer duration of ventilator dependency, and longer ICU and hospital stays—-these factors contribute to greater mortality $[14,15,33]$. The current study enrolled patients from ICUs who were elderly, had high disease severity, and were at high nutrition risk. Most were admitted to the RICU because of pneumonia-related sepsis, septic shock, acute respiratory failure, or acute respiratory distress syndrome. Therefore, adequate nutritional support played a major role in their survival. The nutritional intake cut-off value for distinguishing 
survival from nonsurvival was $65 \%$, the same as that indicated by our other research $[8,13]$. The univariate analysis revealed that the SBEN group experienced mortality benefits, but had a higher SOFA score on the seventh ICU day, and energy intake achievement rate $<65 \%$ on the 10 th ICU day was significantly associated with hospital mortality. However, in the multivariable analysis, the only factor that was discovered to independently predict hospital mortality was energy intake achievement rate $<65 \%$ on the 10 th ICU day (HR, 2.29; 95\% CI, 1.12-4.69). We suggest that the potential mortality benefits from SBEN initiation are due to energy intake improvements in patients with very high disease severity. As such, if energy intake achievement is not improved substantially 3 days after SBEN initiation, supplementary PN or total PN should be considered to increase nutrition support.

This study has several limitations. First, the study design was a retrospective case-controlled study, in which two groups from a database were matched, rather than a prospective randomized controlled trial. Thus, heterogeneity may have existed between the two groups. Second, the study was conducted at a single ICU in a medical center, meaning that the results may not be generalizable. In practice, feeding protocols and patient populations may vary between ICUs. In our RICU, we followed a feeding protocol approved by the registered dietitian, who also provided nutrition risk evaluation and nutrition therapy recommendations in daily practice. For patients with an energy target achievement rate $<50 \%$ or a feeding volume $<750 \mathrm{~mL} /$ day, our protocol has provided the option since 2015 of consulting a gastroenterologist to evaluate the suitability of transpyloric tube insertion for SBEN on the seventh ICU day. Therefore, heterogeneity in ICU care and feeding protocols was minimal in the present study. Third, critically ill patients in ICU may require image studies, such as computed tomography and magnetic resonance imaging, invasive procedures, and gastrointestinal endoscopy, which can interrupt feeding protocols. Finally, the present results may not be generalizable to critically ill patients in pediatric, cardiac, neurosurgical, and surgical ICUs or even general ICUs because the current study was conducted only in RICU patients.

\section{Conclusions}

Replacing NGEN with SBEN on the seventh ICU day significantly improves energy delivery and may reduce hospital mortality risk in patients at high nutritional risk. The key factor determining survival in this population is an energy intake requirement rate $>65 \%$ within 3 days of SBEN initiation. For malnourished, critically ill patients at high nutritional risk (mNUTRIC score $\geq 5$ ) who have been treated with all other available strategies to maximize EN tolerance, we suggest initiating SBEN on the seventh ICU day before PN initiation, and the clinician should follow up on the energy intake achievement rate (at least $>65 \%$ ) 3 days after SBEN initiation to determine the subsequent step of nutrition support therapy.

Supplementary Materials: The following are available online at http://www.mdpi.com/2072-6643/12/7/2009/s1, Figure S1: Study flow chart.

Author Contributions: Conceptualization, P.-K.F.; data curation, W.-N.W., C.-Y.W., and P.-K.F.; formal analysis, W.-N.W. and C.-Y.H.; funding acquisition, P.-K.F.; investigation, W.-N.W., C.-Y.H., and P.-K.F.; methodology, C.-Y.W., C.-Y.H., and P.-K.F.; software, C.-Y.H.; validation, C.-Y.W.; visualization, W.-N.W. and P.-K.F.; writing-original draft, P.-K.F.; writing-review and editing, W.-N.W., C.-Y.W., C.-Y.H., and P.-K.F. All authors read and approved the final manuscript.

Funding: This study was supported by the Taichung Veterans General Hospital (TCVGH-1094404C).

Acknowledgments: This study was based in part on data from the Taichung Veterans General Hospital Research Database, which is managed by the Clinical Informatics Research \& Development Center of Taichung Veterans General Hospital. This manuscript was edited by Wallace Academic Editing. An abstract of these findings has been submitted to the conference "Nutrition 2020" held by the American Society for Nutrition (ASN) on 30 January 2020. We thank Wei-Ning Wang for presenting the preliminary data in June 2020. The abstract has also been published in the journal of "Current Developments in Nutrition", Volume 4, Issue Supplement_2, June 2020, Page 1152 [34].

Conflicts of Interest: The authors declare no conflict of interest. 


\section{Abbreviations}

The following abbreviations are used in this manuscript:

$\begin{array}{ll}\text { APACHE II } & \text { Acute Physiology and Chronic Health Evaluation II } \\ \text { ASPEN } & \text { American Society for Parenteral and Enteral Nutrition } \\ \text { CCI } & \text { Charlson Comorbidity Index } \\ \text { ESPEN } & \text { European Society for Clinical Nutrition and Metabolism } \\ \text { SBEN } & \text { Small bowel enteral nutrition } \\ \text { mNUTRIC } & \text { modified Nutrition Risk in Critically Ill } \\ \text { NGEN } & \text { Nasogastric tube enteral nutrition } \\ \text { PN } & \text { Parenteral nutrition } \\ \text { SCCM } & \text { Society of Critical Care Medicine } \\ \text { SOFA } & \text { Simplified Organ Failure Assessment }\end{array}$

\section{References}

1. Weijs, P.J.M.; Mogensen, K.M.; Rawn, J.D.; Christopher, K.B. Protein Intake, Nutritional Status and Outcomes in ICU Survivors: A Single Center Cohort Study. J. Clin. Med. 2019, 8, 43. [CrossRef] [PubMed]

2. Mogensen, K.M.; Robinson, M.K.; Casey, J.D.; Gunasekera, N.S.; Moromizato, T.; Rawn, J.D.; Christopher, K.B. Nutritional Status and Mortality in the Critically Ill. Crit. Care Med. 2015, 43, 2605-2615. [CrossRef] [PubMed]

3. Kopp Lugli, A.; de Watteville, A.; Hollinger, A.; Goetz, N.; Heidegger, C. Medical Nutrition Therapy in Critically Ill Patients Treated on Intensive and Intermediate Care Units: A Literature Review. J Clin. Med. 2019, 8, 1395. [CrossRef] [PubMed]

4. Havens, J.M.; Columbus, A.B.; Seshadri, A.J.; Olufajo, O.A.; Mogensen, K.M.; Rawn, J.D.; Salim, A.; Christopher, K.B. Malnutrition at Intensive Care Unit Admission Predicts Mortality in Emergency General Surgery Patients. J. Parenter. Enter. Nutr. 2018, 42, 156-163. [CrossRef] [PubMed]

5. Singer, P.; Blaser, A.R.; Berger, M.M.; Alhazzani, W.; Calder, P.C.; Casaer, M.P.; Hiesmayr, M.; Mayer, K.; Montejo, J.C.; Pichard, C.; et al. ESPEN guideline on clinical nutrition in the intensive care unit. Clin. Nutr. 2019, 38, 48-79. [CrossRef]

6. Taylor, B.E.; McClave, S.A.; Martindale, R.G.; Warren, M.M.; Johnson, D.R.; Braunschweig, C.; McCarthy, M.S.; Davanos, E.; Rice, T.W.; Cresci, G.A.; et al. Guidelines for the Provision and Assessment of Nutrition Support Therapy in the Adult Critically Ill Patient: Society of Critical Care Medicine (SCCM) and American Society for Parenteral and Enteral Nutrition (A.S.P.E.N.). Crit. Care Med. 2016, 44, 390-438. [CrossRef]

7. McClave, S.A.; Taylor, B.E.; Martindale, R.G.; Warren, M.M.; Johnson, D.R.; Braunschweig, C.; McCarthy, M.S.; Davanos, E.; Rice, T.W.; Cresci, G.A.; et al. Guidelines for the Provision and Assessment of Nutrition Support Therapy in the Adult Critically Ill Patient: Society of Critical Care Medicine (SCCM) and American Society for Parenteral and Enteral Nutrition (A.S.P.E.N.). J. Parenter. Enter. Nutr. 2016, 40, 159-211. [CrossRef]

8. Wang, W.N.; Yang, M.F.; Wang, C.Y.; Hsu, C.Y.; Lee, B.J.; Fu, P.K. Optimal Time and Target for Evaluating Energy Delivery after Adjuvant Feeding with Small Bowel Enteral Nutrition in Critically Ill Patients at High Nutrition Risk. Nutrients 2019, 11, 645. [CrossRef]

9. Rattanachaiwong, S.; Zribi, B.; Kagan, I.; Theilla, M.; Heching, M.; Singer, P. Comparison of nutritional screening and diagnostic tools in diagnosis of severe malnutrition in critically ill patients. Clin. Nutr. 2020, in press. [CrossRef]

10. De Vries, M.C.; Koekkoek, W.K.; Opdam, M.H.; van Blokland, D.; van Zanten, A.R. Nutritional assessment of critically ill patients: Validation of the modified NUTRIC score. Eur. J. Clin. Nutr. 2018, 72, 428-435. [CrossRef]

11. Sioson, M.S.; Martindale, R.; Abayadeera, A.; Abouchaleh, N.; Aditianingsih, D.; Bhurayanontachai, R.; Chiou, W.C.; Higashibeppu, N.; Mat Nor, M.B.; Osland, E.; et al. Nutrition therapy for critically ill patients across the Asia-Pacific and Middle East regions: A consensus statement. Clin. Nutr. ESPEN 2018, 24, 156-164. [CrossRef] [PubMed]

12. Arabi, Y.M.; Al-Dorzi, H.M.; Mehta, S.; Tamim, H.M.; Haddad, S.H.; Jones, G.; McIntyre, L.; Solaiman, O.; Sakkijha, M.H.; Sadat, M.; et al. Association of protein intake with the outcomes of critically ill patients: A post hoc analysis of the PermiT trial. Am. J. Clin. Nutr. 2018, 108, 988-996. [CrossRef] [PubMed] 
13. Wang, C.Y.; Fu, P.K.; Huang, C.T.; Chen, C.H.; Lee, B.J.; Huang, Y.C. Targeted Energy Intake Is the Important Determinant of Clinical Outcomes in Medical Critically Ill Patients with High Nutrition Risk. Nutrients 2018, 10, 1731. [CrossRef]

14. Jung, Y.T.; Park, J.Y.; Jeon, J.; Kim, M.J.; Lee, S.H.; Lee, J.G. Association of Inadequate Caloric Supplementation with 30-Day Mortality in Critically Ill Postoperative Patients with High Modified NUTRIC Score. Nutrients 2018, 10, 1589. [CrossRef]

15. Wang, C.Y.; Huang, C.T.; Chen, C.H.; Chen, M.F.; Ching, S.L.; Huang, Y.C. Optimal Energy Delivery, Rather than the Implementation of a Feeding Protocol, May Benefit Clinical Outcomes in Critically Ill Patients. Nutrients 2017, 9, 527. [CrossRef] [PubMed]

16. Schuetz, P.; Stanga, Z. Nutritional Management and Outcomes in Malnourished Medical Inpatients in 2020: The Evidence Is Growing! J. Clin. Med. 2019, 9, 27. [CrossRef] [PubMed]

17. Allen, K.; Hoffman, L. Enteral Nutrition in the Mechanically Ventilated Patient. Nutr. Clin. Pract. 2019, 34, 540-557. [CrossRef]

18. Bendavid, I.; Zusman, O.; Kagan, I.; Theilla, M.; Cohen, J.; Singer, P. Early Administration of Protein in Critically Ill Patients: A Retrospective Cohort Study. Nutrients 2019, 11, 106. [CrossRef]

19. Davies, A.R.; Morrison, S.S.; Bailey, M.J.; Bellomo, R.; Cooper, D.J.; Doig, G.S.; Finfer, S.R.; Heyland, D.K. A multicenter, randomized controlled trial comparing early nasojejunal with nasogastric nutrition in critical illness. Crit. Care Med. 2012, 40, 2342-2348. [CrossRef]

20. Acosta-Escribano, J.; Fernandez-Vivas, M.; Grau Carmona, T.; Caturla-Such, J.; Garcia-Martinez, M.; Menendez-Mainer, A.; Solera-Suarez, M.; Sanchez-Paya, J. Gastric versus transpyloric feeding in severe traumatic brain injury: A prospective, randomized trial. Intensive Care Med. 2010, 36, 1532-1539. [CrossRef]

21. Hsu, C.W.; Sun, S.F.; Lin, S.L.; Kang, S.P.; Chu, K.A.; Lin, C.H.; Huang, H.H. Duodenal versus gastric feeding in medical intensive care unit patients: A prospective, randomized, clinical study. Crit. Care Med. 2009, 37, 1866-1872. [CrossRef] [PubMed]

22. White, H.; Sosnowski, K.; Tran, K.; Reeves, A.; Jones, M. A randomised controlled comparison of early post-pyloric versus early gastric feeding to meet nutritional targets in ventilated intensive care patients. Crit. Care 2009, 13, R187. [CrossRef] [PubMed]

23. Montejo, J.C.; Grau, T.; Acosta, J.; Ruiz-Santana, S.; Planas, M.; Garcia-De-Lorenzo, A.; Mesejo, A.; Cervera, M.; Sanchez-Alvarez, C.; Nunez-Ruiz, R.; et al. Multicenter, prospective, randomized, single-blind study comparing the efficacy and gastrointestinal complications of early jejunal feeding with early gastric feeding in critically ill patients. Crit. Care Med. 2002, 30, 796-800. [CrossRef] [PubMed]

24. Rahman, A.; Hasan, R.M.; Agarwala, R.; Martin, C.; Day, A.G.; Heyland, D.K. Identifying critically-ill patients who will benefit most from nutritional therapy: Further validation of the "modified NUTRIC" nutritional risk assessment tool. Clin. Nutr. 2016, 35, 158-162. [CrossRef] [PubMed]

25. Heidegger, C.P.; Berger, M.M.; Graf, S.; Zingg, W.; Darmon, P.; Costanza, M.C.; Thibault, R.; Pichard, C. Optimisation of energy provision with supplemental parenteral nutrition in critically ill patients: A randomised controlled clinical trial. Lancet 2013, 381, 385-393. [CrossRef]

26. Pradelli, L.; Graf, S.; Pichard, C.; Berger, M.M. Supplemental parenteral nutrition in intensive care patients: A cost saving strategy. Clin. Nutr. 2018, 37, 573-579. [CrossRef]

27. Gavri, C.; Kokkoris, S.; Vasileiadis, I.; Oeconomopoulou, A.C.; Kotanidou, A.; Nanas, S.; Routsi, C. Route of nutrition and risk of blood stream infections in critically ill patients; a comparative study. Clin. Nutr. ESPEN 2016, 12, e14-e19. [CrossRef]

28. Doig, G.S.; Simpson, F.; Sweetman, E.A.; Finfer, S.R.; Cooper, D.J.; Heighes, P.T.; Davies, A.R.; O’Leary, M.; Solano, T.; Peake, S. Early parenteral nutrition in critically ill patients with short-term relative contraindications to early enteral nutrition: A randomized controlled trial. JAMA 2013, 309, 2130-2138. [CrossRef]

29. Braunschweig, C.L.; Freels, S.; Sheean, P.M.; Peterson, S.J.; Perez, S.G.; McKeever, L.; Lateef, O.; Gurka, D.; Fantuzzi, G. Role of timing and dose of energy received in patients with acute lung injury on mortality in the Intensive Nutrition in Acute Lung Injury Trial (INTACT): A post hoc analysis. Am. J. Clin. Nutr. 2017, 105, 411-416. [CrossRef]

30. Mukhopadhyay, A.; Henry, J.; Ong, V.; Leong, C.S.; Teh, A.L.; van Dam, R.M.; Kowitlawakul, Y. Association of modified NUTRIC score with 28-day mortality in critically ill patients. Clin. Nutr. 2017, 36, 1143-1148. [CrossRef] 
31. Arabi, Y.M.; Aldawood, A.S.; Al-Dorzi, H.M.; Tamim, H.M.; Haddad, S.H.; Jones, G.; McIntyre, L.; Solaiman, O.; Sakkijha, M.H.; Sadat, M.; et al. Permissive Underfeeding or Standard Enteral Feeding in Highand Low-Nutritional-Risk Critically Ill Adults. Post Hoc Analysis of the PermiT Trial. Am. J. Respir. Crit. Care Med. 2017, 195, 652-662. [CrossRef] [PubMed]

32. Compher, C.; Chittams, J.; Sammarco, T.; Nicolo, M.; Heyland, D.K. Greater Protein and Energy Intake May Be Associated With Improved Mortality in Higher Risk Critically Ill Patients: A Multicenter, Multinational Observational Study. Crit. Care Med. 2017, 45, 156-163. [CrossRef] [PubMed]

33. Alberda, C.; Gramlich, L.; Jones, N.; Jeejeebhoy, K.; Day, A.G.; Dhaliwal, R.; Heyland, D.K. The relationship between nutritional intake and clinical outcomes in critically ill patients: Results of an international multicenter observational study. Intensive Care Med. 2009, 35, 1728-1737. [CrossRef] [PubMed]

34. Wang, W.N.; Fu, P.K.; Hsu, C.Y. Comparison of Feeding Efficacy and Hospital Mortality Between Small Bowel and Nasogastric Tube Enteral Nutrition in Critical Illness at High Nutritional Risk. Curr. Dev. Nutr. 2020, 4, 1152. [CrossRef]

(C) 2020 by the authors. Licensee MDPI, Basel, Switzerland. This article is an open access article distributed under the terms and conditions of the Creative Commons Attribution (CC BY) license (http://creativecommons.org/licenses/by/4.0/). 